\section{Undergraduate Biology Education Research Gordon Research Conference: A Meeting Report}

\author{
Erin L. Dolan, ${ }^{1 *}$ Michelle Borrero, ${ }^{2}$ Kristine Callis-Duehl, ${ }^{3}$ \\ Miranda M. Chen Musgrove, ${ }^{4}$ Joelyn de Lima, ${ }^{5}$ Isi Ero-Tolliver, ${ }^{6}$ Laci M. Gerhart, ${ }^{7}$ \\ Emma C. Goodwin, ${ }^{8}$ Lindsey R. Hamilton, ${ }^{9}$ Meredith A. Henry, ${ }^{10}$ Jose Herrera, ${ }^{11}$ \\ Bethany Huot, ${ }^{12}$ Stacey Kiser, ${ }^{13}$ Melissa E. Ko, ${ }^{14}$ Marcy E. Kravec, ${ }^{15}$ Mark Lee, ${ }^{16}$ \\ Lisa B. Limeri, ${ }^{1}$ Melanie E. Peffer, ${ }^{17}$ Debra Pires, ${ }^{18}$ Juan S. Ramirez Lugo, ${ }^{2}$ \\ Starlette M. Sharp, ${ }^{19}$ and Nicole A. Suarez ${ }^{20}$ \\ ${ }^{1}$ Department of Biochemistry and Molecular Biology, University of Georgia, Athens, GA 30602; \\ 2Department of Biology, University of Puerto Rico, Rio Piedras Campus, San Juan, PR 00931; \\ ${ }^{3}$ Education Research and Outreach, Donald Danforth Plant Science Center, St. Louis, MO 63123; \\ ${ }^{4}$ Department of Ecology and Evolutionary Biology, University of Tennessee, Knoxville, TN 37996; \\ ${ }^{5}$ Department of Plant Biology, Michigan State University, East Lansing, MI 48824; ${ }^{6}$ Department of \\ Biological Sciences, Hampton University, Hampton, VA 23666; ${ }^{7}$ Department of Evolution and \\ Ecology, University of California, Davis, Davis, CA 95616; ${ }^{8}$ Department of Biology, Portland State

 \\ Denver, CO 80217; ${ }^{10}$ Department of Chemistry, Emory University, Atlanta, GA 30322; ${ }^{11}$ Office of \\ the Provost, Mercy College, Dobbs Ferry, NY 10522; ${ }^{12}$ Biological Sciences Program, Michigan State \\ University, East Lansing, MI 48824; ${ }^{13}$ Science Division, Lane Community College, Eugene, OR \\ 97405; ${ }^{14}$ Thinking Matters Program, Stanford University, Stanford, CA 94305; ${ }^{15}$ Department of \\ Biological Sciences, Florida International University, Miami, FL 33199; ${ }^{16}$ Department of Biology, \\ Spelman College, Atlanta, GA 30314; ${ }^{17}$ Molecular, Cellular, and Developmental Biology, University \\ of Colorado Boulder, Boulder, CO 80309; ${ }^{18}$ Department of Life Sciences Core Education, \\ University of California, Los Angeles, Los Angeles, CA 90095; ${ }^{19}$ Department of Curriculum and \\ Instruction-Science Education, Pennsylvania State University, University Park, PA $16802 ;{ }^{20} \mathrm{Center}$ \\ for Research in Mathematics and Science Education, University of California, San Diego, and San \\ Diego State University, San Diego, CA 92120
}

\begin{abstract}
The 2019 Undergraduate Biology Education Research Gordon Research Conference (UBER GRC), titled "Achieving Widespread Improvement in Undergraduate Education," brought together a diverse group of researchers and practitioners working to identify, promote, and understand widespread adoption of evidence-based teaching, learning, and success strategies in undergraduate biology. Graduate students and postdocs had the additional opportunity to present and discuss research during a Gordon Research Seminar (GRS) that preceded the GRC. This report provides a broad overview of the UBER GRC and GRS and highlights major themes that cut across invited talks, poster presentations, and informal discussions. Such themes include the importance of working in teams at multiple levels to achieve instructional improvement, the potential to use big data and analytics to inform instructional change, the need to customize change initiatives, and the importance of psychosocial supports in improving undergraduate student well-being and academic success. The report also discusses the future of the UBER GRC as an established meeting and describes aspects of the conference that make it unique, both in terms of facilitating dissemination of research and providing a welcoming environment for conferees.
\end{abstract}

There is a preponderance of evidence regarding how to teach and mentor diverse groups of students in ways that promote their conceptual understanding, their development as scientists, and their success in college and beyond (Hrabowski, 2011;
CBE Life Sci Educ June 1, 2020 19:mr1 DOI:10.1187/cbe.19-09-0188

*Address correspondence to: Erin L. Dolan (eldolan@uga.edu)

(c) 2020 E. L. Dolan et al. CBE-Life Sciences Education (c) 2020 The American Society for Cell Biology. This article is distributed by The American Society for Cell Biology under license from the author(s). It is available to the public under an Attribution-Noncommercial-Share Alike 3.0 Unported Creative Commons License (http://creativecommons.org/licenses/ by-nc-sa/3.0)

"ASCB@" and "The American Society for Cell Biology®" are registered trademarks of The American Society for Cell Biology. 
TABLE 1. Meeting participant summary: Counts of individuals who applied and were accepted to the three UBER GRCs held thus far, including how many ultimately participated and counts and percent representation by gender and position type, compared with available information for the most recent SABER meeting

\begin{tabular}{|c|c|c|c|c|}
\hline & UBER GRC 2015 & UBER GRC 2017 & UBER GRC 2019 & SABER $^{\text {a }} 2019$ \\
\hline Applications & 262 & 252 & 334 & NA \\
\hline Acceptances & 247 & 228 & 242 & NA \\
\hline Participants & 192 & 188 & 195 & 425 \\
\hline Men & $28 \%(54)$ & $29 \%(56)$ & $24 \%(47)$ & n.d. \\
\hline Women & $72 \%(138)$ & $71 \%(132)$ & $76 \%(148)$ & n.d. \\
\hline Graduate students & $2 \%(4)$ & $5 \%(10)$ & $15 \%(27)$ & $20 \%(86)$ \\
\hline Postdoctoral associates & $5 \%(10)$ & $8 \%(15)$ & $12 \%(22)$ & $14 \%(58)$ \\
\hline Assistant professors & $20 \%(38)$ & $22 \%(41)$ & $17 \%(31)$ & n.d. \\
\hline Associate professors & $23 \%(44)$ & $19 \%(36)$ & $18 \%(30)$ & n.d. \\
\hline Professors & $17 \%(33)$ & $17 \%(32)$ & $14 \%(36)$ & n.d. \\
\hline Faculty (total) & $60 \%(115)$ & $58 \%(109)$ & $50 \%(97)$ & $50 \%(212)$ \\
\hline $\begin{array}{l}\text { Others (administrators, publishers, } \\
\text { program directors, etc.) }\end{array}$ & $33 \%(63)$ & $28 \%(54)$ & $25 \%(49)$ & n.d. \\
\hline
\end{tabular}

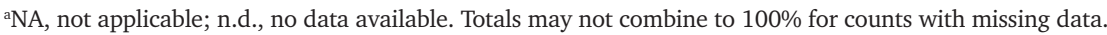

TABLE 2. Institutional representation summary: Counts and percentages of individuals who were speakers, poster presenters, and attendees at the three UBER GRCs held thus far, compared with available information for the most recent SABER meeting

\begin{tabular}{|c|c|c|c|c|}
\hline & \multicolumn{3}{|c|}{ UBER GRC 2019} & \multirow[b]{2}{*}{ SABER 2019 attendees $^{\mathrm{a}}$} \\
\hline & Speakers & Poster presenters & Attendees & \\
\hline 2-year colleges & $4(10 \%)$ & $12(9 \%)$ & $17(9 \%)$ & $32(8 \%)$ \\
\hline Historically black colleges and universities & $2(5 \%)$ & $2(2 \%)$ & $3(1.5 \%)$ & - \\
\hline Master's-granting universities & $2(5 \%)$ & $13(10 \%)$ & $18(9 \%)$ & - \\
\hline Doctorate-granting universities & $24(59 \%)$ & $84(6 \%)$ & $114(58 \%)$ & - \\
\hline Professional societies & $2(5 \%)$ & $3(2 \%)$ & $5(2.5 \%)$ & - \\
\hline Research institutes & $1(2 \%)$ & 0 & $3(1.5 \%)$ & - \\
\hline International & 0 & $2(2 \%)$ & $3(1.5 \%)$ & - \\
\hline Other & 0 & 0 & $1(0.5 \%)$ & - \\
\hline Total & 41 & 131 & 195 & 425 \\
\hline
\end{tabular}

aFor the SABER 2019 meeting, information was available only for 2-year college affiliates.

Singer and Smith, 2013; Freeman et al., 2014; Gentile et al., 2017). Yet there remains only modest uptake of these evidence-based practices (Stains et al., 2018). This year's Undergraduate Biology Education Research Gordon Research Conference (UBER GRC), titled "Achieving Widespread Improvement in Undergraduate Education," addressed this issue by bringing together a diverse group of researchers and practitioners working to identify, promote, and understand widespread adoption of evidence-based teaching, learning, and success strategies in undergraduate biology. For this conference, "improvement" meant a shift toward widespread use of effective and inclusive teaching, training, and mentoring in undergraduate biology education, also called "second-order change" (Argyris and Schon, 1974; Kezar, 2014; Corbo et al., 2016).

Although there are other national conferences focused on undergraduate biology education research (e.g., the annual meeting of the Society for the Advancement of Biology Education Research [SABER]; Lo et al., 2019), there are a few unique features and a different organizational structure that make the UBER GRC distinctive. The meeting offers a combination of pre- sentations on big picture issues, themes, and directions for the field, as well as talks and posters on research and evaluation studies in biology education. For example, representatives of the National Science Foundation (NSF) and several professional societies have attended and presented at the meeting since its inception (Tables 1 and 2). The meeting is longer in duration, following the 5-day, nine-session GRC structure in which the entire group gathers for every session, meals, and social events. The meeting program features diverse types of sessions, including a combination of plenary talks, research talks, and poster sessions highlighting unpublished work; discussions facilitated by leaders in undergraduate biology education; and networking among established and up-and-coming scholars. The meeting also includes sessions geared to discussion about the experiences of women and other historically marginalized groups in science (Power Hour, described later in this report) and to support early-career scholars (Gordon Research Seminar, described later in this report). GRC has a strict confidentiality policy that prohibits any recording of talks or other forms of documentation or dissemination of data shared during the meeting. This 
policy is part of what makes the GRC a unique conference, because it is meant to encourage participants to share unpublished results, works in progress, and negative results that might not otherwise be available to the community.

The 195 conferees at the 2019 UBER GRC represented a range of disciplinary backgrounds beyond biology, biology teaching, and biology education research. ${ }^{1}$ For instance, conferees identified as developmental psychologists, learning scientists, and members of other professions in undergraduate science, technology, engineering, and mathematics (STEM) education not limited to biology. Conferees also represented a range of position types and career stages, including graduate students, postdoctoral scholars, faculty in contingent and tenure-track positions, administrators of diverse ranks (department heads, deans, provosts, directors of centers for teaching and learning), and representatives of funding agencies and education-focused nonprofit agencies (Tables 1 and 2). In general, conferees came to the meeting to achieve multiple goals, including building their awareness and understanding of current educational research and resources as well as to network and form collaborations with both established and up-and-coming researchers and practitioners.

While GRC rules strictly prohibit photographing or otherwise documenting presentations, many posters included brochures, QR codes, paper citations, contact information, and social media handles, allowing participants to learn more about these projects through publicly available information and to connect outside of the GRC for possible future collaborations. GRC gave permission to publish this report of the meeting topics, atmosphere, and participant numbers and demographics, with the stipulation that none of the data presented during the meeting be included in the report.

In this meeting report, we provide a brief overview of the meeting and its history. We also highlight multiple themes that emerged across the presentations and discussions as well as preliminary plans for the 2021 UBER GRC.

\section{HISTORY OF THE MEETING}

The UBER GRC was first offered in 2015 with leadership from Gordon Uno (University of Oklahoma) and Susan Elrod (Indiana University South Bend). To broadly appeal to potential speakers and conferees in the biology education space, the organizers specified no theme aside from the focus on undergraduate biology education. A wide range of topics were presented at the 2015 meeting, including curricular design, student success, teaching improvement, and measuring student outcomes. Driven by suggestions from the community, the 2017 UBER GRC focused on improving diversity, equity, and learning in undergraduate biology education. Presentations and discussions centered around describing the diversity landscape, including trends in student populations, teaching practices, and equity and diversity policies. Other topics discussed at the 2017 meeting included creating more inclusive environments; evaluating strategies and programs for improving diversity, equity, and inclusion; and understanding mechanisms of change in

\footnotetext{
${ }^{1}$ We have named speakers but not poster presenters in this report. The full program, including speaker names, organizations, and talk titles, can be found here: www.grc.org/undergraduate-biology-education-research-conference/2019 Speakers can be contacted directly about the content of their presentations.
}

higher education. The 2019 UBER GRC theme emerged from this last topic, with the aim of promoting deeper discussion and sharing of data and ideas related to fostering widespread change in higher education toward effective and inclusive undergraduate biology education.

\section{MEETING OVERVIEW}

Sylvia Hurtado (University of California, Los Angeles) and David Asai (Howard Hughes Medical Institute [HHMI]) kicked off the 2019 meeting by offering different perspectives on change in undergraduate biology education. Hurtado proposed a new model on instructional change that outlined how data can be used to change minds and ultimately change behavior. She further emphasized that, for educational data to change minds and behaviors, it needs to be coupled with external pressures and incentives, training and development, buy-in through collegial relationships, accountability, and leadership support. Asai moved the focus to boots on the ground by taking up the charge of developing a new introductory biology curriculum that moved away from content coverage and toward core concepts and science practice. This focus on rethinking introductory science course work is one of the themes of HHMI's Inclusive Excellence 3 funding initiative, now underway. ${ }^{2}$

Given the theme of the meeting, a major focus of the talks and posters was on individual- and institution-level supports for and constraints on greater use of evidence-based instruction. Speakers shared insights into how tangible institutional structures, such as annual review, promotion, and tenure, and intangible elements, such as teaching beliefs and trust between students and instructors, can influence the degree to which instructors effectively apply active learning and to which students reap the benefits. Collectively, the scientific content of the meeting indicated that the field of biology education research is beginning to move beyond the mechanics of active learning to the need to examine and account for the culture of higher education to achieve more effective and inclusive instruction.

Both practitioners and researchers emphasized the importance of action from all levels of the academic institution, from faculty and department heads to senior leadership, in order to achieve widespread improvement of undergraduate education. One strategy offered by speakers included meeting and communicating often with stakeholders to receive and offer guidance on elements that influence progress toward change, such as during faculty teaching evaluations, recruitment and hiring, and resource allocation. Speakers also emphasized the importance of maximizing the effectiveness of change initiatives by involving teams, rather than single change agents.

\section{INNOVATIVE USES OF DATA}

Several speakers presented work on large data sets, which they argued have largely untapped potential for maximizing student success within courses and degree programs. For instance, David Micklos (Cold Spring Harbor Laboratory) spoke about how existing scientific data sets can be used in courses to engage students in research. Tim McKay (University of Michigan) and Tim Renick (Georgia State University) both spoke about the

\footnotetext{
${ }^{2}$ www.hhmi.org/science-education/programs/inclusive-excellence-new -competition-announcement
} 
ways their institutions use course-level or student-level data to identify anomalies in student performance and tailor interventions to reduce performance gaps and better support students in making progress toward degree completion.

\section{LESSONS LEARNED FROM COMMUNITY COLLEGES}

Community colleges (CCs) represent a wide array of institutional environments with student profiles that closely reflect the ongoing shift in student demographics toward an older and more ethnically and socially diverse student population. More than half of the students who ultimately receive a STEM undergraduate degree spend part of their student experience at a CC. Yet, by most generous estimates, only $3 \%$ of research articles in undergraduate biology education include CC contexts (Schinske et al., 2017). Talks both within a CC-focused session and by CC faculty speakers during other sessions sought to address this gap by highlighting initiatives designed to support CC students in successfully pursuing their desired educational and career paths. James Hewlett (Finger Lakes Community College) spoke about the Community College Undergraduate Research Initiative $\left(\mathrm{CCURI}^{3}\right)$, which is a network of community colleges across the country that engage undergraduates in research experiences in the form of course-based undergraduate research experiences (CUREs), program-wide undergraduate research experiences, and summer undergraduate research experiences. CCURI institutions have experienced varying levels of success in creating sustainable undergraduate research programs. Research is currently underway to identify factors that promote or constrain CCs in shifting from a culture of "no research" to one in which research is an integral part of the CC student experience.

Jenny McFarland (Edmonds Community College) shared data on a STEM support program that assists CC college students in moving past early failure in gateway STEM courses, and Erin Shortlidge (Portland State University) presented data from a STEM support program aimed to reduce transfer shock for CC students moving from 2- to 4-year institutions. Elements that appeared to be important in these success programs include peer support, cocurricular activities, and participation in undergraduate research experiences, which improved student perceptions of inclusion in the scientific and academic community. Jeff Schinske (Foothill College) presented the Community College Biology Instructor Network to Support Inquiry into Teaching and Education Scholarship, which engages CC faculty in designing and carrying out education research in CC settings with CC students through a combination of professional development, mentorship, and networking. ${ }^{4}$ The success of these and other initiatives was apparent in the many posters on display at the GRC that detailed the efforts of CCs to improve undergraduate biology education and to provide research experiences to their students.

\section{UNDERGRADUATE RESEARCH}

Undergraduate research was a prevalent topic in talks and posters, with an emphasis on how undergraduate research experiences can maximize diversity, equity, and inclusion in STEM. Many posters presented studies of the effectiveness of CUREs in increasing students' computational proficiency as well as their

\footnotetext{
${ }^{3}$ www.ccuri.org.

${ }^{4}$ https://qubeshub.org/community/groups/ccbioinsites.
}

confidence and identities as scientists. Other posters about CUREs focused on their potential to increase gender equity; decrease "plant blindness"; and enable hands-on, inquiry-based elements for online courses. There were several examples of the impact of CUREs on self-efficacy and in promoting equity for different student populations (majors, nonmajors, first years, underrepresented minorities, etc.). These were implemented in multiple scenarios using a wide range of research projects, some of which involved the use of CRISPR/Cas9 technology and microbe identification. Other poster presenters examined how students developed scientific skills such as scientific argumentation, reasoning, and critical thinking in formats other than undergraduate research. These approaches included guided-inquiry learning and online platforms such as Quizfolio.

\section{CUSTOMIZING CHANGE INITIATIVES}

Many of the speakers and poster presenters related their work to Vision and Change core concepts and competencies and took a community-centric approach in their design and development (American Association for the Advancement of Science [AAAS], 2011). Yet multiple speakers and presenters also emphasized the need to customize change initiatives. For example, Mark Lee (Spelman College) spoke about his approach to inclusive hiring and retention, which draws from the self-determination theory of motivation (Ryan and Deci, 2000). This theory posits that individuals are more motivated if they have some control over their situations (autonomy), they feel capable of being successful (competence), and they feel connected to the people around them (relatedness). He argued for keeping new faculty teaching loads light for the first semester while they gained teaching competence, which also functioned to give them autonomy in developing their research agenda before taking on additional teaching and service duties. Susan Elrod (Indiana University South Bend) provided her perspective on the challenges of institutional change, especially at a large institution. She argued that a university is a system and that faculty may not have a good understanding of what makes this system work. She posited that, when change leaders understand the inputs, workings, and outputs of the system, they can work within it or alter it to achieve desired changes. Elrod then spoke about "moves" that change leaders need to make and how these "moves" might differ by the level at which the change has to occur. Alix Fink (Longwood University) concluded the session by giving a practical example of customized change. She spoke about the Partnership for Undergraduate Life Sciences Education (PULSE) Ambassadors program..$^{5}$ This program works with departments to identify the capacities of a department, envision outcomes of transformation, and develop strategies to use available capacities in order to achieve transformation. All three speakers commented on the need to first determine what individuals, departments, and institutions need to achieve change, and then figure out how to change the existing system to meet needs.

\section{PROFESSIONAL DEVELOPMENT}

Elisabeth Schussler (University of Tennessee, Knoxville), Brian Sato (University of California, Irvine), Gili Marbach-Ad (University of Maryland, College Park), and Katerina Thompson (University of Maryland, College Park) spoke about effective

${ }^{5}$ www.pulsecommunity.org/page/ambassador-program-1. 
professional development at all levels of undergraduate biology education, including graduate student teaching assistants, faculty, and administrators. Collectively, they emphasized that institutions can support professional development by establishing reward structures for participation and by making even modest gestures that indicate professional development is valued, such as providing food at professional development meetings. They also emphasized the importance of relating professional development to personal experience and of building a strong sense of community among the participants. They argued that the goals of professional development sessions should be to build awareness about students, to stimulate conversation and sharing of resources related to teaching and learning, and to foster connections between teaching centers and departments.

An important trend was the significant role of organizations and entities other than colleges and universities as catalysts for change. Among these were BioQUEST, CBE-Life Sciences Education, CourseSource, the National Association of Biology Teachers, and Quantitative Undergraduate Biology Education and Synthesis. ${ }^{6}$ The general perception was that these entities are continually developing and improving their platforms to provide faculty with support to teach effectively and inclusively. The speakers explained that making effective use of resources from these organizations requires professional development at all levels. Highlighted initiatives to provide this professional development included: undergraduate peer-learning assistants and graduate teaching assistants, Science Teaching Experience for Postdoctoral scholars, faculty development on active learning, and support for departmental change through the PULSE network.

\section{UNDERSTANDING AND MAXIMIZING DIVERSITY, EQUITY, AND INCLUSION}

Presenters also addressed a range of issues regarding diversity, equity, and inclusion. Speakers discussed the need for diverse, equitable, and inclusive environments at both the student and faculty levels, within research environments, and at all types of institutions. Several conferees presented on specific active-learning strategies that fostered students' sense of belonging in the classroom and in the STEM disciplines. Many different departmental interventions and organizations were discussed that aimed to create diverse and well-resourced faculty, including Aspire Alliance ${ }^{7}$ and Science Education for New Civic Engagements and Responsibilities. ${ }^{8}$

Speakers Sarah Eddy (Florida International University), Isi Ero-Tolliver (Hampton University), and Michael Feder (AAAS) challenged attendees to think beyond traditional and current approaches to diverse and equitable education. Eddy highlighted the need to consider values and aspirations of individual students, rather than just the context of their learning, in order to promote learning and success of all students. Ero-Tolliver focused on bringing CUREs to underserved institutions such as historically black colleges and universities. Feder presented on the work being done by the AAAS to promote inclusive teaching through reward and research structures, such as the STEM

\footnotetext{
${ }^{6} \mathrm{https}$ //qubeshub.org.

${ }^{7}$ http://aspirealliance.org.

${ }^{8} \mathrm{http}: / /$ sencer.net.
}

Equity Achieving Change (SEA-Change) program. ${ }^{9}$ In framing this challenge, the speakers emphasized the importance of teaching-focused professional development and the role of change agents in conceptualizing and tackling departmental and institutional change. These same topics were echoed in many of the other talks over the course of the meeting.

Tracie Addy (Lafayette College), Ellen Carpenter (NSF), and Kimberly Tanner (San Francisco State University) concluded the meeting with a session on inclusion in undergraduate biology education. Addy described work she is leading to identify factors that predict whether instructors implement inclusive teaching approaches as well as their reasoning for doing so. Echoing elements of HHMI's Inclusive Excellence 3 initiative, Addy urged the community to define a vision for an inclusive institution, noting that shared vision is critical for institutional transformation (Henderson et al., 2011). Carpenter spoke about the NSF's investment in undergraduate biology education and commended the community's exemplary use of resources. She said that the NSF sought to support inclusive, creative, novel, and transformative research. The types of research suitable for funding include identifying what "works" (or not) in biology education, generating new knowledge about biology teaching and learning, broadening participation and maximizing inclusion in STEM, understanding adaptation of education-based practices, and facilitating sustainability in projects. Tanner spoke at a personal level about inclusion as a first-generation college student herself, and how this informs her research and her efforts to foster inclusion in biology education. She argued that great science requires diverse perspectives, but that these perspectives are often excluded by traditional approaches to teaching and education. She spoke about the potential for a novel, relatively simple methodology, the Decibel Analysis for Research in Teaching, to reveal teaching patterns that faculty could use to reflect on their teaching and track changes over time (Owens et al., 2017).

\section{POWER HOUR}

In addition to the scientific content sessions, UBER GRC hosted a "Power Hour" facilitated by Rebecca Price (University of Washington Bothell). The Power Hour aims to be an open forum for discussing ways in which women are marginalized, although the discussion was inclusive of all individuals who are made to feel like they are not equal or valued or do not belong in higher education environments in STEM. The most notable themes that emerged were the discomfort and rage caused by marginalizing experiences and the fear of reporting or confronting perpetrators. These feelings were amplified by either the overt or implied hierarchy in which marginalizing experiences occurred. Specifically, the greater the hierarchical difference, the greater the fear of reporting the incident and the greater the likelihood that it would not be reported. The group discussed how graduate students in particular quickly opted to remain silent in fear of retribution. Discussions of remaining quiet or providing quiet support were contrasted with the value of clearly verbalizing the inappropriate behavior that occurred. The session concluded with practical advice on how to navigate marginalizing experiences, including acknowledging that if it feels wrong, it probably is (i.e., self-validating feelings) and

\footnotetext{
${ }^{9}$ https://seachange.aaas.org
} 
finding allies to discuss and support as needed. Furthermore, the community must:

- address marginalizing behavior, because it will not "just go away";

- recognize power differentials in order to bring the conversation out of the hierarchy and onto the human level;

- acknowledge that all are entitled to feel equal and there is a need to find ways to speak up and help change marginalizing cultures; and

- assume responsibility regardless of connection to the transgression.

\section{GORDON RESEARCH SEMINAR}

The UBER GRC included a Gordon Research Seminar (GRS) for the first time this year. This 2-day event, which immediately preceded the GRC, was designed to be a platform to increase participation of graduate students and postdoctoral scholars who represent the future of research in the discipline. The GRS featured four talk sessions and two poster sessions, all presented by early-career researchers.

The GRS began with a discussion of students' social psychological experiences in the classroom fueled by talks from Katelyn Cooper (University of Central Florida) and Meredith Henry (Emory University). Cooper discussed students' experiences with anxiety in the classroom and Henry discussed students' experiences with failure. These talks highlighted the influence of factors other than cognitive skills in student well-being and success. They also highlighted the need to create environments that promote positive affect and social experiences in the classroom, especially with relation to failure experiences.

The second science session focused on graduate students' teaching experiences and their teaching professional development. Miranda Chen Musgrove (University of Tennessee, Knoxville) began the session by characterizing how graduate students cope with both research and teaching anxiety. Joshua Reid (Middle Tennessee State University) then discussed how graduate students navigate their dual research and teaching identities. Collectively, these talks explored the unique challenges and experiences of educators who are also students themselves. Lorelei Patrick (University of Minnesota Twin Cities) and Rita Margarida Magalhaes (Rochester Institute of Technology) addressed factors that influence pedagogical decision making of both graduate students and faculty. These discussions emphasized the importance of professional development for early-career scholars as a lever for reforming undergraduate education.

The third science session focused on the development and application of instructional tools. This session was a unique blend of research and practice, relevant to the broad range of GRS participants' interests and backgrounds. Alexa Clemmons (University of Washington, Seattle) presented BioSkills, ${ }^{10}$ a guide to learning objectives aligned with Vision and Change core competencies. Megan Shiroda (Michigan State University) presented on Automated Assessment of Constructed Response, ${ }^{11}$ a tool that summarizes the content of students' responses to constructed-response questions. Both speakers discussed their

\footnotetext{
${ }^{10} \mathrm{https}$ //qubeshub.org/qubesresources/publications/1305/3.

${ }^{11} \mathrm{https}$ ///beyondmultiplechoice.org.
}

research on the use of these tools as well as practical tips for implementation for practitioners.

The last science session focused on students' psychosocial experiences in the classroom. Both talks emphasized the importance of considering students' perspectives in the classroom and how they may differ from the perspectives of instructors or researchers. Staci Johnson (Clemson University) presented on her work on students' learning approaches, highlighting how students may interpret the wording of a survey differently from the researchers who designed it and the instructors who implement it. Claire Meaders (Cornell University) presented her work on how students from different backgrounds may have different expectations when they enter their introductory college courses and the problems that may arise when their expectations are not met.

The GRS poster presentations showcased an array of research topics, including research on faculty promotion, incorporating quantitative and interdisciplinary pedagogical practices into CUREs, strategies for teaching professional development, and STEM career development. The range of topics highlighted the diversity in scholarship among the GRS community, including discipline-based education researchers tackling fundamental questions and primarily bench scientists engaging in the scholarship of teaching and learning.

\section{GRS MENTORING SESSION}

Professional development for early-career scientists was both a goal and a research theme for the GRS. To this end, the second day of the GRS began with a mentoring session, in which four field leaders led discussions and guided activities designed to advance the professional development of GRS participants. David Asai (HHMI) led a discussion about mentoring that focused on how to mentor students and how to manage relationships with one's own mentors. Stacey Kiser (Lane Community College) led a discussion about conference networking, which focused on setting specific networking and professional development goals for a meeting. Rebecca Price (University of Washington Bothell) and Sarah Eddy (Florida International University) co-led a session about crafting job application materials to leverage one's different professional identities (e.g., educator, researcher, biologist).

In each session, participants engaged in reflective activities about the topic to advance their professional development. For example, in the conference networking session, participants reflected on their career goals over the next 5 years, generated two to three concrete and measurable goals for the meeting, and discussed these in small groups. Participants' feedback indicated that engaging in this reflective exercise before a conference helped them maintain focus and progress toward their networking and professional development goals.

\section{MEETING VALUE}

Although this meeting report is not intended as an evaluation of the meeting per se, it is informative to draw attention to what the UBER GRC participants saw as the unique value of the meeting. Statements about the value of the GRS and GRC reflect the perspectives of the authors of this meeting report and their informal conversations with other conferees rather than any systematic measurement of meeting value. Our intention in sharing these perspectives is to equip readers with information 
to make a more informed decision about whether to attend a future UBER GRC meeting.

Graduate students and postdoctoral scholars who had an interest in education research but little to no experience with it commented on how the meeting provided an opportunity to learn about the nature of this research and make connections with the researchers. Faculty who were transitioning from the natural sciences into discipline-based education research also found that the meeting provided a supportive introduction to the field and an environment that afforded opportunities to make connections.

The GRS offered newcomers to the field of undergraduate biology education research an opportunity to quickly build a network and become incorporated into a community of peers. The GRS consisted of a smaller group of attendees ( $~ 50$ compared with $\sim 200$ at the GRC). Most of these individuals also attended the GRC, which allowed conferees several days (1.5day GRS + 5-day GRC) to build networks and reinforce their sense of community during the larger GRC.

More experienced scholars appreciated that individuals working in UBER were using theories from psychology and other social science disciplines to frame their work. This progress was viewed as increasing the potential contributions that individuals outside biology could make in the undergraduate biology education space. The diversity of institutional types represented at the GRC was also perceived to be a rich source of knowledge for what works in education as well as how and why it works. The fact that the meeting included instructors and was not limited to scholars allowed for awareness building about the current and urgent matters educators are facing and the array of tools and resources that have been developed to address these matters. Ideas could be exchanged between researchers and practitioners about strategies for promoting student learning and development. Conferees found themselves on both sides of this conversation-sharing ideas and adapting strategies to different courses, institutions, or goals. Conferees felt these conversations were far more detailed and personalized than the recommendations that can be gleaned from a website or publication, and they frequently ended with an invite to reconnect via email after the conference. Prior UBER GRC participants commented on the strong sense of community that developed at the meeting and continued beyond it.

Regardless of disciplinary perspective, conferees noted several aspects of the UBER GRC that made it a unique conference environment. First, they appreciated that the conference focused on the use of data to make decisions in undergraduate biology education. Conferees found themselves surrounded by like-minded science educators who valued the power of evidence-based teaching practices and who could learn from one another. Conferees also found the meeting a friendly place to share preliminary work, and they appreciated the developmental nature of the discussions. Early-career scholars and individuals new to UBER noted that their participation and contributions felt valued. They also noted that the conference was useful for becoming familiar with current trends in the discipline and with establishing a foothold in the community.

All GRC meetings are designed to be immersive experiences that promote deep discussion about research and foster networking and collaboration. This is accomplished by holding meetings in secluded areas with on-site housing, communal meals, and ample time for discussion and by ensuring both early-career and established scholars are among the conferees. The meeting is small enough to deeply engage with others around the research, yet large enough to offer some diversity in terms of research interests. All participants attend the same sessions, so there is a strong shared experience. Communal meals allow for the ideas that are presented in the oral sessions and posters to be discussed in detail among the participants and with the presenters more informally. The poster sessions are more active and engaged than the majority of other conferences and frequently inspire discussion beyond the projects presented. Moreover, the length of the meeting affords the luxury of time to think about, explore, and cultivate ideas.

Finally, the leadership of GRCs is expected to fundraise in order to cover as many of the conference costs as possible. This includes writing proposals to federal and philanthropic agencies and seeking donations from industry and individuals to support costs not allowed by certain granting agencies. Depending on the success of these efforts, the funds enable participation of individuals who do not have dedicated grant or department funds for conference travel, which promotes the inclusivity of the meeting.

\section{NEXT STEPS}

The UBER GRC was just promoted from "probationary" to "continuing" status, which means that it will now recur every 2 years, as long as attendance remains strong and evaluations positive. All GRCs are probationary for at least two offerings, and the decision to shift to a recurring meeting must be made after the third offering (i.e., 2019). This decision was based on multiple factors, including the number of applications, the number of participants, and the evaluation results, including feedback from conferees and on-site staff. The next UBER GRC is scheduled for June 27-July 2, 2021 at Bates College (Lewiston, ME); Erin Dolan (University of Georgia) and Stacey Kiser (Lane Community College) were elected to be cochairs, and Stanley Lo (University of California, San Diego) and Carrie Diaz Eaton (Bates College) were elected to be co-vice chairs. The associated GRS will be held June 25-26; Starlette M. Sharp (Pennsylvania State University) and Miranda Chen Musgrove (University of Tennessee, Knoxville) were elected as chair and vice chair of the 2021 GRS.

As in previous offerings of the UBER GRC, the 2021 meeting will focus on a topic that emerged from the community: navigating transitions in undergraduate biology education. This theme is grounded in research in undergraduate biology education that indicates that students, educators, and researchers must transition across learning environments, institutions, programming, and types of work to be successful. For instance, students transition from precollege to college education, from 2-year to 4-year colleges, from learning about discoveries in classrooms to producing discoveries in the lab and the field, and from being students to becoming professionals in their desired careers. Educators transition from doctoral and postdoctoral training that emphasizes development of biological expertise to careers that require expertise in curricula, instruction, and student development. Furthermore, biology education researchers transition from training in education or in biological research to 
studying teaching and learning in biology per se. Finally, students, educators, and researchers in undergraduate biology education can experience transitions that may align with or develop their identities or clash with or undermine their identities. The 2021 UBER GRC will feature cutting-edge, unpublished research from high-profile and emerging scholars studying these and other transition points in the undergraduate biology education space.

\section{ACKNOWLEDGMENTS}

The UBER GRS and GRC were supported in part by funding from the HHMI, the National Institute of General Medicine Sciences of the National Institutes of Health (NIH) under award number 1R13GM134534-01, and the NSF Division of Undergraduate Education Award 1922648. The content is solely the responsibility of the authors and does not necessarily represent the official views of the HHMI, NSF, or NIH. Thanks also to Mary Pat Wenderoth for providing participant information for the 2019 SABER meeting.

\section{REFERENCES}

American Association for the Advancement of Science. (2011). Vision and change in undergraduate biology education: A call to action. Washington, DC.

Argyris, C., \& Schon, D. A. (1974). Theory in practice: Increasing professional effectiveness. Oxford, UK: Jossey-Bass.

Corbo, J. C., Reinholz, D. L., Dancy, M. H., Deetz, S., \& Finkelstein, N. (2016). Framework for transforming departmental culture to support educational innovation. Physical Review Physics Education Research, 12(1), 010113. https://doi.org/10.1103/PhysRevPhysEducRes.12.010113

Freeman, S., Eddy, S. L., McDonough, M., Smith, M. K., Okoroafor, N., Jordt, H., \& Wenderoth, M. P. (2014). Active learning increases student performance in science, engineering, and mathematics. Proceedings of the National Academy of Sciences USA, 111(23), 8410-8415. https://doi. org/10.1073/pnas.1319030111

Gentile, J., Brenner, K., \& Stephens, A. (2017). Undergraduate research experiences for STEM students: Successes, challenges, and opportunities. Washington, DC: National Academies Press. Retrieved May 17, 2017, from www.nap.edu/catalog/24622/undergraduate-research-experiences -for-stem-students-successes-challenges-and-opportunities

Henderson, C., Beach, A., \& Finkelstein, N. (2011). Facilitating change in undergraduate STEM instructional practices: An analytic review of the literature. Journal of Research in Science Teaching, 48(8), 952-984. https:// doi.org/10.1002/tea.20439

Hrabowski, F. A. (2011). Expanding underrepresented minority participation: America's science and technology talent at the crossroad. Washington, DC: National Academies Press. Retrieved December 18, 2016, from www.nap.edu/catalog/12984/expanding-underrepresented-minority - participation-americas-science-and-technology-talent-at

Kezar, A. (2014). Higher education change and social networks: A review of research. Journal of Higher Education, 85(1), 91-125. https://doi.org/10 1080/00221546.2014.11777320

Lo, S. M., Gardner, G. E., Reid, J., Napoleon-Fanis, V., Carroll, P., Smith, E., \& Sato, B. K. (2019). Prevailing questions and methodologies in biology education research: A longitudinal analysis of research in CBE-Life Sciences Education and at the Society for the Advancement of Biology Education Research. CBE-Life Sciences Education, 18(1), ar9. https:// doi.org/10.1187/cbe.18-08-0164

Owens, M. T., Seidel, S. B., Wong, M., Bejines, T. E., Lietz, S., Perez, J. R., ... Tanner, K. D. (2017). Classroom sound can be used to classify teaching practices in college science courses. Proceedings of the National Academy of Sciences USA, 114(12), 3085-3090. https://doi.org/10.1073/ pnas.1618693114

Ryan, R. M., \& Deci, E. L. (2000). Intrinsic and extrinsic motivations: Classic definitions and new directions. Contemporary Educational Psychology, 25(1), 54-67. https://doi.org/10.1006/ceps.1999.1020

Schinske, J. N., Balke, V. L., Bangera, M. G., Bonney, K. M., Brownell, S. E., Carter, R. S., ... \& Corwin, L. A. (2017). Broadening participation in biology education research: Engaging community college students and faculty. CBE-Life Sciences Education, 16(2), mr1. https://doi.org/10.1187/ cbe.16-10-0289

Singer, S., \& Smith, K. A. (2013). Discipline-based education research: Understanding and improving learning in undergraduate science and engineering. Journal of Engineering Education, 102(4), 468-471. https:// doi.org/10.1002/jee.20030

Stains, M., Harshman, J., Barker, M. K., Chasteen, S. V., Cole, R., DeChenne-Peters, S. E., ... \& Young, A. M. (2018). Anatomy of STEM teaching in North American universities. Science, 359(6383), 1468-1470. https:// doi.org/10.1126/science.aap8892 